American Journal of Applied Sciences 9 (9): 1496-1502, 2012

ISSN 1546-9239

(C) 2012 Science Publication

\title{
Effects of Temperature and Flow Rates of Ozone Generator on the DBD by Varying Various Electrical Parameters
}

\author{
${ }^{1}$ Lakshminarayanan Vaduganathan, \\ ${ }^{2}$ Balakrishnan Anantharaman Poonamallie, ${ }^{3}$ Mahendran Nagalingam \\ ${ }^{1}$ Depterment of EEE, \\ Dr. Mahalingam College of Engineering and Technology, Pollachi,TN, India \\ ${ }^{2}$ Depterment of Academic and Research, \\ KCG College of Engineering and Technology, Chennai, TN, India \\ ${ }^{3}$ Depterment of EEE, Mahendra College of Engineering, Salem, TN, India
}

\begin{abstract}
This study rationale a high voltage power supply which varies of $(\mathrm{O}-5) \mathrm{kV}$ with the variable frequency of $50 \mathrm{~Hz}-5 \mathrm{kHz}$. The power supply is used in the dielectric barrier discharge tube for the ionization process to yield concentration of ozone.This setup points the development of small and high efficient ozone generators using corona discharge method. Ozone generation was carried out by varying parameters including voltage, frequency, flow rate and temperature to yield high concentration of ozone. The feeding gas composition greatly affected the ozone generation rate, which was increased in order of ambient air to dry air. With increase in temperature, ozone concentration is increased while ozone generation rate is enhanced. In the experiments, a maximum ozone concentration of approximately $83 \mathrm{ppm}$ is obtained, the peak value of applied voltage of about $5 \mathrm{kV}$ and gap of electrode is $4.3 \mathrm{~mm}$ respectively. Dry air is used as feeding gas with residence time of $10.58 \mathrm{sec}$.
\end{abstract}

Key words: Ozone analyzer and air compressor, Temperature sensor (LM35), Ferrite core transformer, Corona discharge method

\section{INTRODUCTION}

Ozone, historically mainly used for the treatment of drinking water, is one of the strongest oxidizing and bleaching agents and it has definite advantages over other commercial oxidants, namely, no undesirable byproducts or residues are formed. Since the on-site production of the ozone requires only air and electricity no transport of potentially dangerous chemicals is involved in the ozone applications. These are the main reasons why the ozone is increasingly used for many kinds of oxidizing processes.

Tropospheric ozone is the major ingredient in photochemical smog and, Control Household Odors, Control Indoor Air Pollution, Cigarette Cigar Smoke Elimination, Mold Control and Removal, Hotel/Motel Room Odor Removal and so on. This represents a considerable risk to vegetation and human beings. Effects of ozone may occur at various levels of organization, i.e., from the cellular level through the level of individual organs and plants to the level of plant communities and ecosystems.

Ozone is major and important air pollutant in many parts of the world like North America, Europe, East Asia, South Asia and central Africa. $\mathrm{O}_{3}$ is a secondary pollutant, as it is not directly emitted from sources.
Nitrogen Oxides $\left(\mathrm{NO}_{\mathrm{x}}\right)$ and Volatile Organic Compound (VOCs) are the primary pollutant precursors for $\mathrm{O}_{3}$ and the combine effect of increasing methane $\left(\mathrm{CH}_{4}\right)$ Carbon monoxide (CO) has elevated tropospheric $\mathrm{O}_{3}$ levels.

The following factors are important for ozone formation:

- VOCs volatile organic compounds: mostly emitted by motor vehicles, vegetation, industries, commercial dry cleaners and paints

- $\mathrm{NO}_{\mathrm{x}}$ : emitted from motor vehicles, power plants, industrial facilities, biomass burning and lightning

- High sunlight, temperature and low wind speed play important roles in the formation of ozone

- The highest $\mathrm{O}_{3}$ concentrations can be found in the summer during dry high pressure conditions. During inversions (warm air above cooler air) pollutants often get trapped resulting in high ozone concentrations

The energy range being used to produce ozone gas from chemical components is from 493-762.23 kJ $\mathrm{moL}^{-1}$. The adapting unit has the required energy within the range from $5.583-8.631 \mathrm{kWh} \mathrm{m}^{-3}$. Since there is only $21 \%$ oxygen in the air, the required energy should be within the range from 1.17243-1.620 kWh $\mathrm{m}^{-3}$. It is enough to generate ozone gas in the gap of two-layer electrodes connected in series.

Corresponding Author: Lakshminarayanan Vaduganathan, Depterment of EEE, Dr. Mahalingam College of Engineering and Technology, Pollachi,TN, India 
The temperature rise of the quartz tube due to the high-frequency dielectric heating destroys the generated ozone. The quartz tube temperature was $90-\mathrm{C}$ for the pyramid-type electrode and $70-\mathrm{C}$ for the screw-type electrode at $4 \mathrm{kV}$ and $21 \mathrm{~min}^{-1}$. A pyramid-type electrode can electrode can generate high ozone concentration $\left(20 \mathrm{~g} \mathrm{~m}^{-3}\right)$ with high efficiency. High ozone treatment rate is obtained at the conditions of long treatment time with low ozone concentration. High gas flow rate is effective to enlarge the treated volume in a short period (Takayamaa et al., 2006).

The ozone generation by atmospheric pulsed discharge is carried out using an electrode covered by different widths of dielectrics with maximum gap width of $9 \mathrm{~mm}$. In the case of the electrode without dielectric, a maximum concentration of about $300 \mathrm{ppm}$. It was found that the ozone concentration and generation yield were improved by the electrode partly covered by the dielectric. Then, using partly covered electrode was more effective than using an electrode covered entirely by the dielectric (Kaneda et al., 2004).

A model simulating ozone synthesis in a DBD reactor is developed in this study. Good agreement is found between the predicted ozone concentrations by the dimension of outer electrode radius $(1.95 \mathrm{~cm})$ and inner electrode radius $(1.55 \mathrm{~cm})$ with dielectric thickness of $2 \mathrm{~mm}$ with applied voltage of $10 \mathrm{kv}$ which yields ozone concentration of about $27 \mathrm{ppm}$ but by varying inner electrode radius of $(1.65 \mathrm{~cm})$ which yields ozone concentration of about $30 \mathrm{ppm}$ (Lee et al., 2004).

The superimposed discharge with the weak positive dc streamer and the surface discharge showed better enhancement for the ozone generation and the efficiency than does the superimposed discharge with the negative dc corona and the surface discharge below $700 \mathrm{~mW} /(\mathrm{L} / \mathrm{min})$. It can be guessed that this phenomenon was caused by large active volume. and superposition effects on ozone generation were saturated around 300 me:

- The maximum efficiency was occurred under the superimposed discharge with the positive dc streamer and the surface discharge. The value was 235.6 $\mathrm{g} / \mathrm{kWh}$ that was almost twice of the efficiency of the individual surface discharge and is almost same as the general level of silent discharge at $1.5 \mathrm{~L} \mathrm{~min}^{-1}$

- Flow rate of $1.5 \mathrm{~L} \mathrm{~min}^{-1}$ was effective on the ozone concentration and the efficiency for each discharge

- The superimposed discharge showed rapid increment of gas temperature from 25.4-40.4 degree Celsius below700 $\mathrm{mW} /(\mathrm{L} / \mathrm{min}$.). The ozone generation by the surface discharge was carried out under low gas temperature variation. Ozone Generation Characteristics of Superimposed Discharge with Surface and DC Discharge
- Although the discharge current of surface discharge occurred during only two-quarter cycle of applied voltage, the discharge current of the superimposed discharge occurred during one cycle of applied voltage. It can be considered that the additional discharge currents of the superimposed discharge occurred during another two-quarter cycle cause the superposition effects (Gibalov and Pietsch, 2006).

Experimental setup: The oxygen feed gas flows through a $14 \mathrm{~mm}$ gap between a tungsten wire of 0.1 $\mathrm{mm}$ diameter and a plate electrode. This gap is larger than the optimum gap $(4.3 \mathrm{~mm})$ of silent discharge. A high $\mathrm{AC}$ voltage for the $\mathrm{AC}$ discharge is applied to the wire electrode. The plate electrode for the surface discharge is composed of single Ruthenium oxide $(\mathrm{RuO})$ strip of $4.3 \mathrm{~mm}$ width on the top ceramic (alumina; Al2O3) surface and two ones of $1 \mathrm{~mm}$ width on the bottom surface. A high ac voltage for the surface discharge is applied to the plate electrode as shown in Fig. 1. Applied voltages were 0 to $5 \mathrm{kV}$ (ac) in the surface discharge.

Including these electrodes, the main reactor was made from acryl to observe discharge aspects by naked eyes. The internal dimension of reactor was $508 \times 16.1 \times 20.3 \mathrm{~mm}$ (Length $\times$ Thickness $\times$ Height). The residual times of oxygen molecule in the reactor are $10.58-3 \mathrm{sec}$ for the flow rate of $2-4.0 \mathrm{~L} \mathrm{~min}^{-1}$.

\section{MATERIALS AND METHODS}

Corona discharge (ozone tube structure): Corona in many forms, including glows and haloes, spots, brushes and streamers. The potential at which corona is found to originate is called corona threshold voltage. Above this voltage, there is a limited region, in which current increases proportionately with voltage. This is called the Ohm's law regime (Ketkaew, 2007). After this region, the current increases more rapidly, leading to the complete breakdown and arcing or sparking at a point called the breakdown potential. Corona discharge is highly dependent on geometry. Electric field intensity is higher around the surface of a charged conductor with higher curvature or lower radii of curvature. If $Q$ is the total charge stored in a conductor and $r$ is its radius of curvature, the electric field intensity $\mathrm{E}$ is inversely proportional to the radius, as given by the following equation, where $\varepsilon_{0}$ is the permittivity of free space (and air) and is equal to $8.852 \times 10^{-12} \mathrm{~F} / \mathrm{m}$. The Gauss's law for the electric field says that the electric flux through any closed surface is proportional to the amount of electric charge contained within that surface. The electric field of a co-core cylinder of length 1 and radius, $r_{1} \leq r \leq r_{2}$, Fig. 1 is given by: 
Am. J. Applied Sci., 9 (9): 1496-1502, 2012

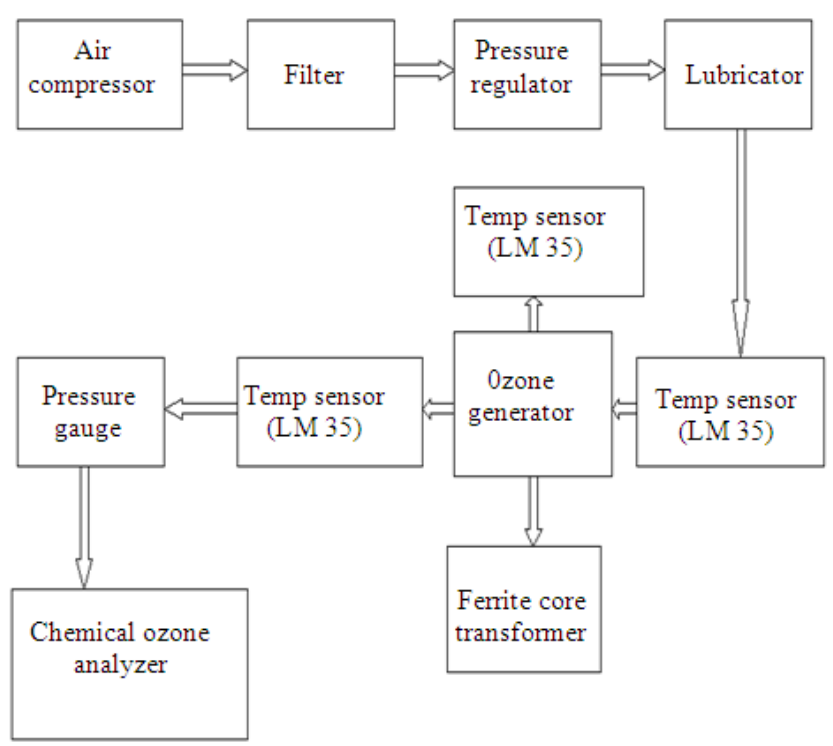

Fig. 1: Experimental setup of ozone generation

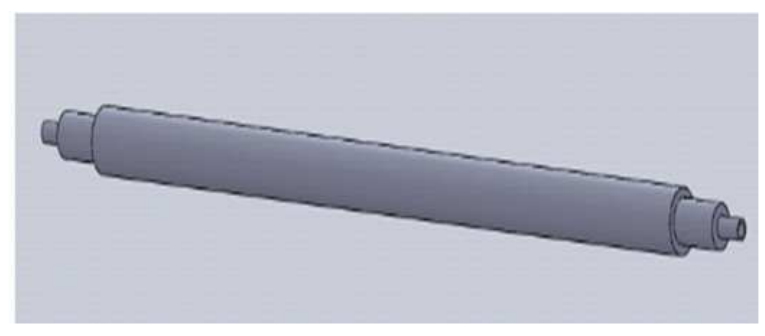

Fig. 2: Electrode tube using solid works

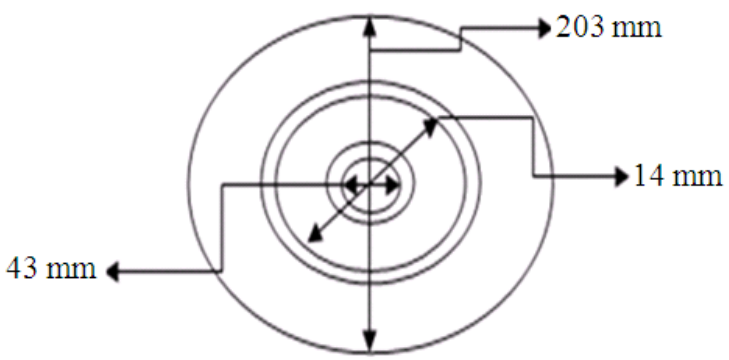

Fig. 3: Dimension of electrode tube

$$
\mathrm{E}(\mathrm{r})=\frac{\mathrm{Q}}{2 \pi \varepsilon \mathrm{rI}}
$$

The maximum electric field stress occurs on the inside of cylinder's surface and is given by:

$$
\mathrm{E}_{\mathrm{MAX}}=\mathrm{E}\left(\mathrm{r}_{1}\right)=\frac{\mathrm{V}}{\mathrm{r}_{1} \operatorname{In} \frac{\mathrm{r}_{2}}{\mathrm{r}_{1}}}
$$

Electrode tube design and energy usage: The principle of ozone tube design relies on an unsmooth electric field for the generation of the ozone gas quantity. Therefore, a two-layer electric insulator is chosen for the electrode design due to the permittivity $(\varepsilon)$ differences of the electric insulator. It is suitable for the generation of a non-uniform electric field to have variable but close to $\varepsilon$ values of each layer under electric field stress. As shown in Fig. 2, a two-layer cocore cylinder for ozone tube design is chosen under the following conditions (Boonseng and Kinnares, 2010):

- Silica is chosen for the 1 st layer electric insulator due to its effectiveness in generating ozone gas, where $\varepsilon_{1}=4.6$, the diameter is $0.43 \mathrm{~cm}$ and the length is $20 \mathrm{~cm}$

- Air is chosen for the 2nd layer electric insulator, where $\varepsilon_{2}=1$

- Cathode frilled aluminum (for rubbing pots) in filament coil inside of the silica's electric insulator is used. The reason is that aluminum has a high conductivity

- The anode is a stainless steel cylinder, where the diameter is $1.4 \mathrm{~cm}$ and the length is $20 \mathrm{~cm}$

- Calculation of Electric Field (E) and Voltage (V) of Ozone Tube

In Fig. 3: $\mathrm{r}_{1}=.43 \mathrm{~cm}, \mathrm{r}_{2}=1.4 \mathrm{~cm}, \mathrm{r}_{3}=2.03 \mathrm{~cm}, 1=$ $50.8 \mathrm{~cm}$. For energies from 5.58 to $7.73 \mathrm{kWh} \mathrm{m}^{-3}$. If the air is composed of $21 \%$ oxygen $\left(\mathrm{O}_{2}\right)$, the chosen energy range is $1.172-1.620 \mathrm{kWh} / \mathrm{m}^{3}$ :

air volume $=\pi\left(\mathrm{r}_{2}-\mathrm{r}_{1}\right)^{2} * \mathrm{I}=10.053 \mathrm{~cm}^{3}$ 
With maximum energy per volume $\left(\mathrm{W}_{\max }\right)$ of 1.620 $\mathrm{kWh} / \mathrm{m}^{3}$ and minimum energy per volume $\left(\mathrm{W}_{\min }\right)$ of $1.172 \mathrm{kWh} / \mathrm{m}^{3}$, then 6 :

$$
\begin{aligned}
& \mathrm{W}_{\text {max }}=1.620 \times 10^{3} \times 10.053 \times 10^{-6}=0.016 \mathrm{Wh} \\
& \mathrm{W}_{\text {min }}=1.172 \times 10^{3} \times 10.053 \times 10^{-6}=0.011 \mathrm{Wh} \\
& \mathrm{E}_{(\max \times \min )}=\sqrt{\frac{2 \mathrm{~W}_{(\max , \min )}}{\text { evol }}} \\
& \mathrm{E}_{\text {min }}=39.972 \mathrm{kV} / \mathrm{Cm} \\
& \mathrm{E}_{\text {min }}=33.143 \mathrm{KV} / \mathrm{Cm}
\end{aligned}
$$

The average value of the breakdown voltage is:

$$
\begin{aligned}
& \mathrm{V}_{\text {Breakdown (avg) }}=\left(\mathrm{E}_{\max }+\mathrm{E}_{\text {min }}\right) / 10 \\
& =(73.115) / 10 \\
& =7.312 \mathrm{kV}
\end{aligned}
$$

Power supply: A high voltage power supply which produces of $5 \mathrm{kv}$ with the variable frequency of $50 \mathrm{~Hz}-5$ $\mathrm{KHz}$. The power supply is used in the dielectric barrier discharge tube for the ionization process. The frequency of the waveform can be varied with the help of resistors and capacitor. It produces a controllable frequency and sinusoidal alternating voltage output. The output of the system is an alternating wave of high voltage and variable frequency with low switching losses and harmonics reduction, eliminating electromagnetic interference. Variable frequency power can be used in various applications such as, Protection from overload currents, ozone generator. The system can be made compact because of the large reduction in size and weight which is shown in Fig. 4.

The amount of energy applied to the gas gap between the electrodes is critical to the concentration of ozone produced. It is a combination of the voltage and frequency that results in a given energy input. Typically, voltages of between 0 to $7 \mathrm{kV}$ are used with frequencies ranging from mains supply of 50 or $60 \mathrm{~Hz}$, medium up to $1000 \mathrm{~Hz}$, (Linsheng et al., 2010) and high up to $4000 \mathrm{~Hz}$. Until recently the most common design was to use mains frequency and vary the voltage. Limitations to this method include:

- High peak voltages increase the stress on the dielectric resulting in more frequent failures

- The ozone output is not linear to the change in applied voltage

$$
\mathrm{P}_{0}=4 \mathrm{f} \mathrm{C}_{\mathrm{d}} \mathrm{V}_{\mathrm{s}}\left(\left(\frac{\mathrm{C}_{\mathrm{d}}+\mathrm{C}_{\mathrm{g}}}{\mathrm{C}_{\mathrm{d}}}\right) \mathrm{V}_{\mathrm{s}}\right)
$$

where, $\mathrm{f}$ is frequency, $\mathrm{C}_{\mathrm{d}}$ is dielectric capacitance, $\mathrm{C}_{\mathrm{g}}$ is gap capacitance, $V_{s}$ is sparking voltage, $V_{0}$ is peak value of driving voltage, $\mathrm{P}$ is gas pressure and $\mathrm{G}$ is Discharge gap:

$$
\mathrm{V}_{\mathrm{s}}=26.55 \mathrm{PG}+1480
$$

These capacitances were calculated considering the dielectric and discharge gaps to be parallel plate capacitors of area equal to the water surface are capacitances of the water layer.

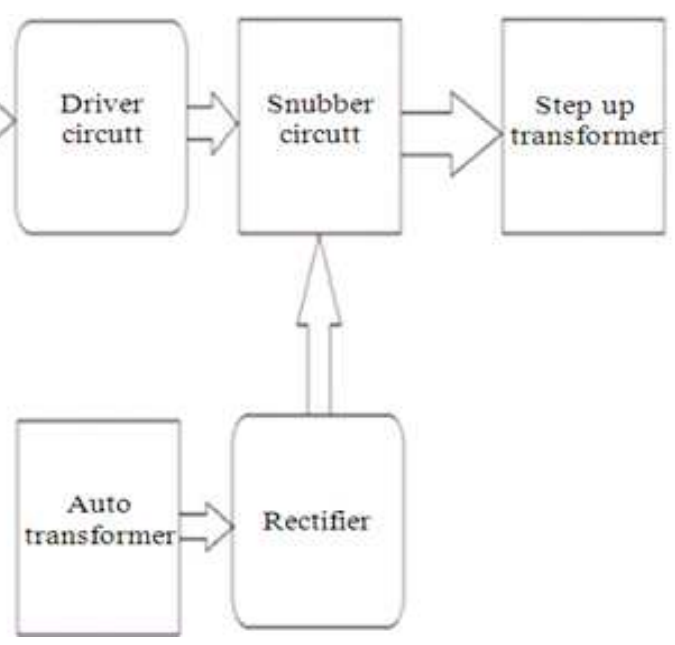

Fig. 4: Block diagram of DC Pulsed High Voltage source for ozone generator 
Ferrite core transformer: Most ferrite materials used in SMPS applications, hysteresis losses dominate up to 300 $\mathrm{KHz}$. At high frequencies eddy current losses take over, because they tend to vary with frequency squared (Kamase et al., 1991) In order to overcome these losses the ferrite core is made of laminated metal alloy and powered metal cores are used:

$$
\mathrm{B}=\left(\mathrm{E}_{\mathrm{rms}} 108\right) /(4.44 \mathrm{f} \mathrm{N} \mathrm{Ae})
$$

Where:

$$
\begin{aligned}
\mathrm{f} & =\text { Frequency } \\
\mathrm{N} & =\text { Turns, } \\
\mathrm{Ae} & =\text { Effective core area }
\end{aligned}
$$

- $\quad$ High Resistivity = low eddy current loss = high usable frequency ranges

- High Magnetic Permeability = high induction in minimal space

- Versatility of core shapes = satisfies magnetic requirements in minimal space

- $\quad$ Light Density = light weight

- Low Cost Relative to Alternative Materials

- Some of advantage compare with other transformers

\section{RESULTS}

Effect of temperature: The ozone concentration and production rate from a constant air flow rate of $2.5 \mathrm{~L}$ $\min ^{-1}$ and Fig. 5 stability of temperature with respect to time at maximum of $5 \mathrm{kv}$ with $5 \mathrm{kHz}$ :

$$
\mathrm{V}_{\mathrm{i}}=3 * 10^{3} \mathrm{a}\left(\frac{\mathrm{T}_{0} \mathrm{P}}{\mathrm{TP}_{0}}+0.3 \sqrt{\frac{10 \mathrm{~T}_{0} \mathrm{P}}{\mathrm{TP}_{0} \mathrm{a}}}\right) \operatorname{In}\left(\frac{4 \mathrm{~d}}{\pi \mathrm{a}}\right)
$$

where, T0 and $\mathrm{P} 0$ are the reference temperature (298 K) and pressure $\left(\begin{array}{lll}101 & 325 \mathrm{~Pa}\end{array}\right)$, respectively. In our experiments, the actual inception voltage generally followed equation except for cases of the relatively small radius $(\mathrm{a}=0.0635 \mathrm{~mm})$ and the relatively large interelectrode gap $(\mathrm{d}=4.3 \mathrm{~mm})$, in which the inception voltage is slightly higher than predicted by equation 10 and which is show in Fig. 6:

$$
\left[\mathrm{O}_{3}\right]=\Delta \mathrm{T}\left(\frac{\mathrm{MC}}{\Delta \mathrm{H}}\right)
$$

where, $\Delta \mathrm{T}$ is differential temperature measured, $\mathrm{M}$ is molecular mass, $\mathrm{C}$ is specific heat gas.

The gas flow rate $(\mathrm{Q}) \sim 16 \mathrm{~ms}$ ) was much greater or much less, the operating conditions commonly used in commercial electrostatic devices.

\section{Effect of pressure:}

Ozone concentration and ozone generation rate: Finally, the gas flow rate itself also affects the ozone generation efficiency because of increasing cooling rate with air cooled ozonizers. The ozone concentration verses applied voltage is shown in Fig. 7 for different LPMs.

It's well known that ozone generation efficiency is enhanced with lowering temperature of a discharge chamber which is shown in the Fig. 8 for different voltage levels:

$$
r=1.96 * 10^{-6}\left(\frac{\mathrm{CQ}}{601}\right)
$$

where, the units of $\mathrm{r}, \mathrm{C}, \mathrm{Q}$ and 1 are $\mathrm{mg}\left(\mathrm{sec}^{-1}\right)$, ppb, $\mathrm{cm}^{3} \min ^{-1}$ and $\mathrm{mm}$, respectively.

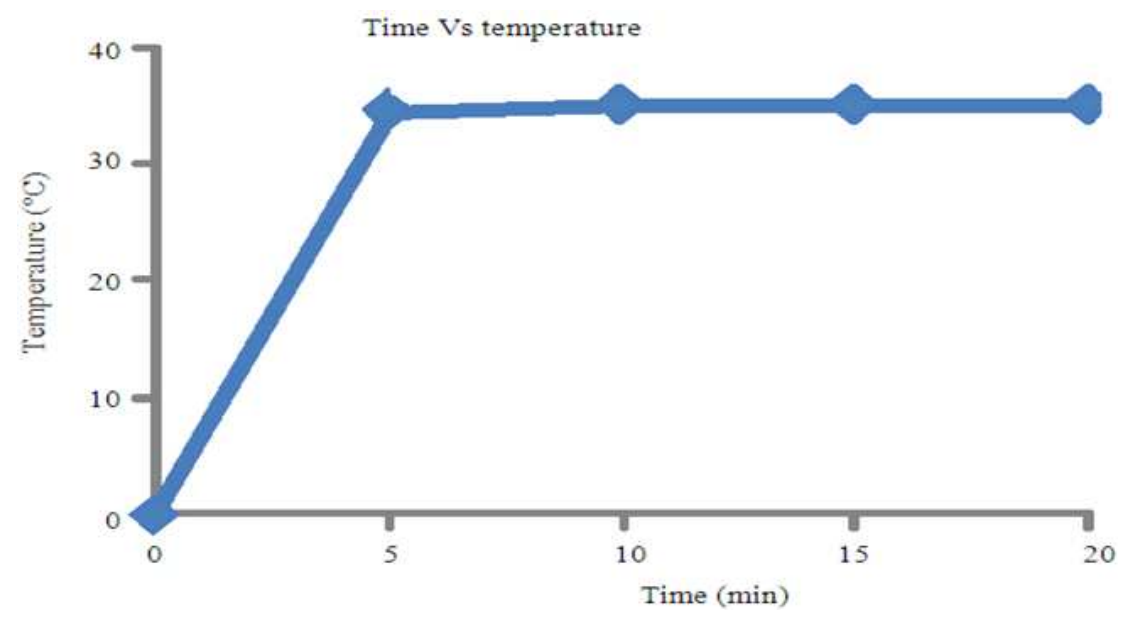

Fig. 5: Stability of temperature with respect to time at maximum of $5 \mathrm{kv}$ with $5 \mathrm{kHz}$ 


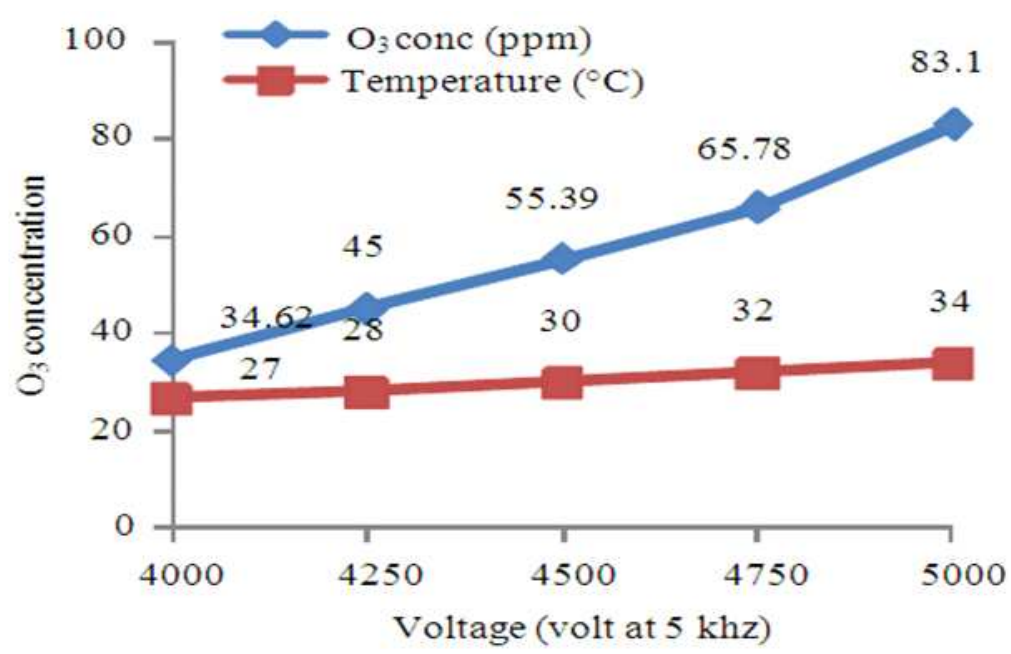

Fig. 6: Concentration of ozone with effect of temperature respect to voltage

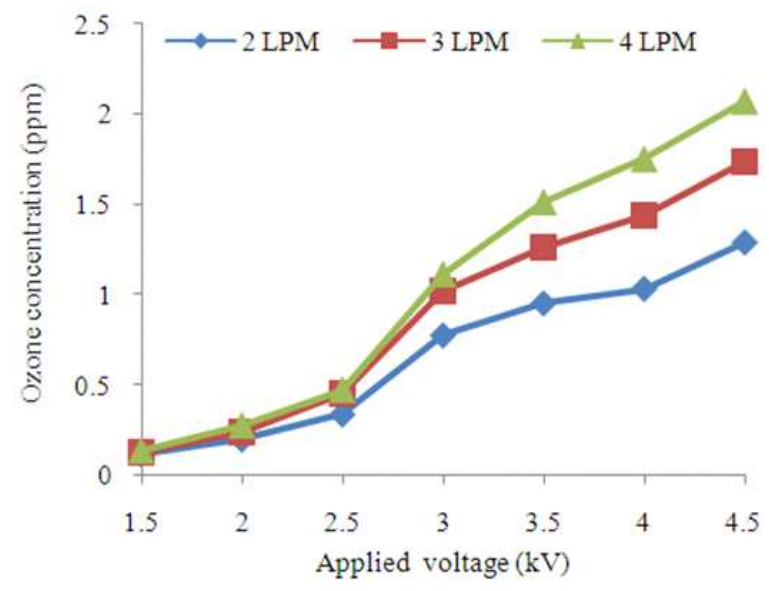

Fig. 7: Ozone concentration Vs flow rate by varying voltage

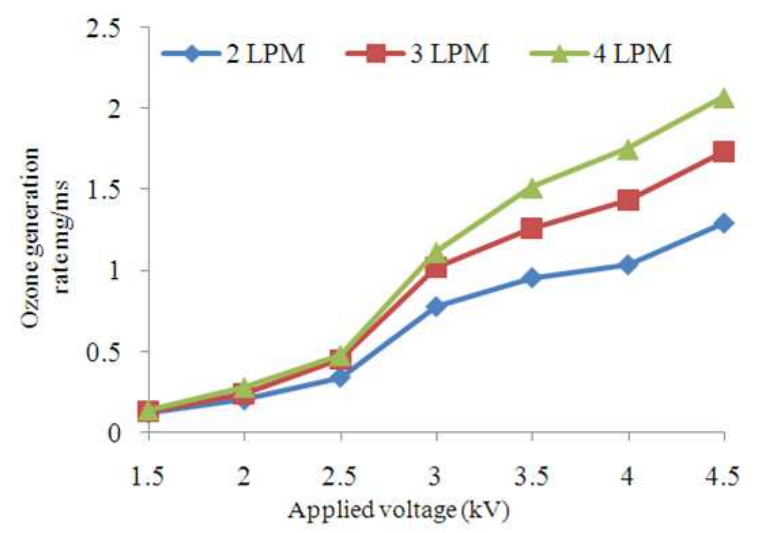

Fig. 8: Ozone Generation rate Vs flow rate by varying voltage

\section{DISCUSSION}

Effect of temperature: By using Boron silicate glass plate it requires 5 mins for the constant variations of temperature. At constant flow rate for each degree of variations the ozone concentration varies linearly. Sudden variations takes place when increase in voltage mean while linear variation takes place when there is change in frequency.

Effect of Pressure(flow rate): Due to the incremental of flow rate the production rate of the ozone increases, where as ozone concentration has pull down as per graphical plot shown in Fig. 8. The breakdown voltage has been reduced by the enhancement of flow rate without changes in the dimensions of the DBD tube, to the maximum of $510^{\circ} \mathrm{C}$ of the glass tube.

\section{CONCLUSION}

The present research is focused on the investigation of the effect of temperature and pressure for ozone concentration and ozone generation rate. In which ozone synthesis and ozone saturation level depends on the dimension of the DBD and temperature. Based on this DBD dimension applied peak voltage can be raised to the maximum of $7.3 \mathrm{kV}$ to prevent them from voltage break down. The saturation level changes more than $1.5 \%$ per each degree of temperature. This means, a decrease of the mean gas temperature of 30 degree Celsius will increase the level of the ozone saturation concentration of about $50 \%$. In the effect of pressure, when the applied constant voltage of $4.5 \mathrm{kV}$ with varying pressure of 2, 3, 4 LPM, with increasing flow rate of feeding gas (Dry air), ozone concentration is reduced from 65-52 ppm, but ozone generation rate is increased from $1.294-2.071 \mathrm{mg} \mathrm{m} \mathrm{sec}^{-1}$. 


\section{REFERENCES}

Boonseng, C. and V. Kinnares, 2010. Harmonic analysis of corona discharge ozone generator using brush electrode configuration. Proceedings of the IEEE Power Engineering Society Winter Meeting, Jan. 23-27, IEEE Xplore Press, pp: 403-408. DOI: 10.1109/PESW.2000.849998

Gibalov, V.I. and G.J. Pietsch, 2006. On the performance of ozone generators working with dielectric barrier discharges. Ozone: Sci. Eng.: J. Int. Ozone Assoc., 28: 119-124. DOI: 10.1080/01919510600559419

Kamase, Y., M. Shimizu, A. Mizuno and T. Nagahama, 1991. Pulsed high voltage source for ozone generator. Proceeding of the Con Conference Record of the 1991 IEEE Industry Applications Society Annual Meeting, Sept. 28-Oct. 4, IEEE Xplore Press, Dearborn, MI, USA, pp: 693-697. DOI: 10.1109/IAS.1991.178312

Kaneda, S., N. Hayashi, S. Ihara, S. Satoh and C. Yamabe, 2004. Application of dielectric material to double-discharge-type ozonizer. Vacuum, 73: 567571. DOI: $10.1016 / j$.vacuum.2003.12.088
Ketkaew, S., 2007. The case study of 5 kHZ-25 kHZ high frequency adjustment in converter circuit to generate ozone gas. AU J.T., 11: 42-47.

Lee, H.M. M.B. Chang and T.C. Wei, 2004. Kinetic modeling of ozone generation via dielectric barrier discharges. Ozone: Sci. Eng.: J. Int. Ozone Assoc., 26: 551-562. DOI: 10.1080/01919510490885361

Linsheng, W., H. Zhaoji, Z. Yafang and W. Qinfen, 2010. Experimental study on ozone generation and ozone oxidation to removal multi-pollutant of flue gas. Proceeding of the 4th International Conference on IEEE Bioinformatics and Biomedical Engineering (iCBBE), Jun. 18-20, IEEE Xplore Press, Chengdu, pp: 1-4. DOI: 10.1109/ICBBE.2010.5515999

Takayamaa, M., K. Ebiharaa, H. Stryczewskaa, T. Ikegami and Y. Gyoutoku et al., 2006. Ozone generation by dielectric barrier discharge for soil sterilization. Thin Solid Films, 506-507: 396-399. DOI: $10.1016 /$ j.tsf.2005.08.332 